\title{
Health belief model predicts adherence to CPAP before experience with CPAP
}

\author{
S. Olsen*, S. Smith ${ }^{\#}$, T. Oei* and J. Douglas ${ }^{\natural}$
}

ABSTRACT: Adherence to continuous positive airway pressure (CPAP) therapy for obstructive sleep apnoea (OSA) is often poor. Biomedical indices explain little of the variance in CPAP use. The present study tested a health belief model of adherence in order to determine the contribution of psychological constructs as compared to biomedical indices in the prediction of CPAP adherence.

Consecutive patients $(n=77)$ newly diagnosed with OSA and naïve to CPAP treatment (had never tried CPAP before) completed questionnaires at baseline (prior to CPAP treatment). The questionnaires assessed: outcome expectancy with treatment, self-efficacy, functional outcomes of sleepiness, and perceived risk of negative health outcomes. Physiological data were obtained from a standard clinical diagnostic sleep study. CPAP adherence was assessed at 4-month follow-up.

Health belief model constructs alone explained $21.8 \%$ of the variance in CPAP adherence, whereas health belief model constructs and biomedical indices together explained $31.8 \%$ of the variance in CPAP adherence. The greatest proportion of CPAP adherence was explained by higher outcome expectancies with treatment, greater functional limitations as a result of sleepiness and lower risk perception.

The results suggest that patients have developed beliefs and expectations about obstructive sleep apnoea and continuous positive airway pressure even before they try continuous positive airway pressure treatment. These beliefs and expectations predict the patients' adherence to effective therapy.

KEYWORDS: Adherence, continuous positive airway pressure treatment, obstructive sleep apnoea, prediction, psychological models

bstructive sleep apnoea (OSA) is a common sleep disorder characterised by collapse of the upper airway during sleep $[1,2]$. The estimated American prevalence of OSA is $4 \%$ in males and $2 \%$ in females [2-4]. OSA incurs high health costs [4], but is often inadequately treated $[4,5]$. Continuous positive airway pressure (CPAP) therapy is the goldstandard treatment for moderate-to-severe OSA. However, the therapy is consistently associated with suboptimal adherence rates $[5,6]$. It has been estimated that $15-30 \%$ of patients do not accept CPAP treatment from the outset [5]. Of those that do initially accept the treatment, 25$50 \%$ fail to adhere optimally [6]. Patients still using CPAP in the long term (up to 5 yrs) can be expected to use their CPAP machine, on average, for 4-5 h.night ${ }^{-1}[7-11]$.
CPAP is often a difficult treatment and requires considerable alteration of a patient's lifestyle. Side-effects of the treatment may include skin irritation, nose stuffiness, air leaks around the mask, claustrophobic reactions to the mask, problems with spontaneous intimacy with the bed partner and the noise of the machine [6]. This side-effect profile led to the belief within the literature that biomedical factors and the mask interface were the source of the problem. However, modifications to the CPAP device that have reduced many of these side-effects have produced only small improvements in objective adherence to this treatment $[12,13]$. Indeed, the evidence suggesting that side-effects predict patient adherence is inconsistent. Further, linear combinations of biomedical indices, including body mass index (BMI), respiratory disturbance

Earn CME accreditation by answering questions about this article. You will find these at the back of the printed copy of this issue or online at www.erj.ersjournals.com/current.shtml

AFFILIATIONS

*School of Psychology,

University of Queensland, St Lucia

\# Centre for Accident Research and Road Safety, Queensland University of Technology, Carseldine, and

- Prince Charles Hospital, Chermside, Australia.

CORRESPONDENCE

S. Olsen

School of Psychology

University of Queensland

St Lucia

4072

Queensland

Australia 406

Fax: 61733654466

E-mail: s.olsen@psy.uq.edu.au

Received:

September 272007

Accepted after revision:

March 202008

STATEMENT OF INTEREST

Statements of interest for T. Oei and S. Smith can be found at www.erj.ersjournals.com/misc/ statements.shtml 
index (RDI) or apnoea/hypopnoea index and CPAP pressure, rarely predict $>10-15 \%$ of the variance in CPAP adherence [7].

Indices of the severity of OSA, for example RDI (a measure of the number of respiratory disturbances, namely apnoeas and hypopnoeas, per hour of sleep), do not reliably correlate with patients' reported subjective symptom severity and quality of life $[2,14]$. This indicates that a patient's subjective perception of the problem may not necessarily reflect the objective severity of the illness, nor their need for treatment. The primary goal of the present article is to present a psychological model of CPAP adherence that predicts patient acceptance of and adherence to treatment.

Recent studies have begun to investigate the utility of psychological models in the prediction of CPAP acceptance and subsequent adherence [13, 15-19]. Patients begin to develop expectations and beliefs regarding OSA and CPAP treatment even before taking the treatment home [20]. Their subjective experience of this treatment, including their propensity to report subjective benefits and side-effects (or barriers) of CPAP use, may be influenced greatly by these early belief systems. This could explain why objective adherence early in the treatment process is among the strongest predictors of subsequent use [15], rather than biomedical indices of disease severity [7]. Simply put, patients do not adhere to the treatment if they have developed expectations and beliefs regarding the treatment that reduce the likelihood that they will try to accept it in the first place.

The present authors propose the health belief model (HBM) [21] as a conceptual basis for understanding patient motivations to accept, and subsequently adhere to, CPAP treatment. This model is predictive of preventative health behaviours (such as wearing a bicycle helmet), and has widespread use in predicting health behaviours in other domains [21, 22]. The $\mathrm{HBM}$ is inclusive in its assessment of potential predictors of adherence, since it allows for the inclusion of demographic variables (class, sex and age) and psychological and psychosocial influences on subsequent action.

The HBM proposes that the patient's readiness to act is contingent upon their perceived susceptibility to illness consequences if left untreated (risk perception) and the perceived seriousness of their illness (impact on current functioning). The patient's belief in the benefit of the proposed treatment is based on their weighting of the perceived benefits to their health if they adhere to the treatment (outcome expectancies) against the perceived barriers to action (such as potential side-effects of the treatment). The patient's selfefficacy (confidence) [22] in being able to use the treatment in the face of barriers, as well as the presence of a cue to action, such as advice from a doctor, encouragement from their spouse, or a mass media campaign [21, 22], are also important in the model.

Figure 1 provides a modified conceptual model of CPAP acceptance and adherence using HBM constructs [21]. Biomedical and psychological variables are conceptualised as having an influence upon the patients' perceived risk of negative health outcomes and perceived severity of the disorder, as well as their weighing of potential benefits and barriers, which could affect their acceptance of the treatment.
However, biomedical and psychological variables are not expected to have a direct influence on treatment acceptance themselves. Self-efficacy is expected to be associated with the patients' perceived benefits of using the treatment (outcome expectancy). HBM predictors of perceived risk, severity, benefits and barriers, in the presence of a cue to action, are expected to directly predict acceptance of CPAP, which, in turn, feeds back to the degree to which patients perceive benefits and barriers to treatment, as well as their perceived disease severity and risk. CPAP acceptance, in combination with the feedback loop to these HBM constructs, predicts which patients will continue to adhere to CPAP treatment at home.

One recent study utilised $\mathrm{HBM}$ constructs in predicting CPAP use [23]. HBM constructs of benefits and barriers were found to be better predictors of CPAP adherence than the objective severity measures of RDI, BMI and CPAP. These findings lend support to the use of HBM constructs in the prediction of CPAP adherence. Moreover, these constructs were predictive after only 1 night of CPAP experience, indicating that the model may be of use in the early prediction of CPAP acceptance and adherence.

The purpose of the present study was to investigate HBM constructs in the prediction of CPAP adherence early in the treatment process, i.e. after a diagnosis of OSA but prior to starting CPAP. The literature to date has been weak regarding good measures of these constructs. Therefore, only existing validated measures of constructs from the model, namely selfefficacy, perceived risk (susceptibility), functional outcomes (severity) and outcome expectancies (benefits), were utilised in the present study. It was expected that measurement of selfefficacy, perceived risk, functional outcomes and outcome expectancies would provide a better psychological predictive model of CPAP acceptance and adherence than the biomedical indices that have been investigated to date.

\section{METHODS}

\section{Participants}

The participants were consecutive patients diagnosed with OSA [1, 3] recruited through a major public hospital in

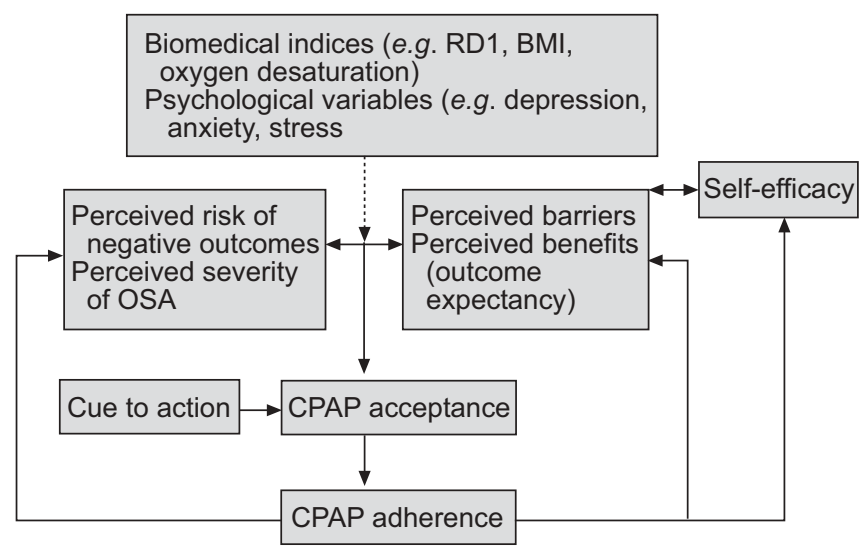

FIGURE 1. A conceptual model of continuous positive airway pressure (CPAP) adherence. The nature of the various relationships is indicated by arrows (-----: weak; —.: moderate-to-strong). RDI: respiratory disturbance index; BMI: body mass index; OSA: obstructive sleep apnoea. Modified from [21]. 
Brisbane (the Prince Charles Hospital, Chermside, Australia). Patients were referred to the hospital by their general practitioner. Additional inclusion criteria included a recommendation by the treating sleep physician for CPAP treatment and that the patient had not previously tried CPAP treatment. Exclusion criteria included being aged $<18$ yrs or an inability to give informed consent (due to intellectual impairment or severe mental illness). The sample consisted of 77 patients (47 males and 30 females) with a mean \pm SD age of $55.25 \pm 12.39$ yrs (range 26-80 yrs). Their BMI was 35.11 \pm 8.30 (19.5-56) and their RDI was $38.36 \pm 25.85$ events $\cdot h^{-1}\left(5.6-124\right.$ events $\left.\cdot h^{-1}\right)$. Of the patients, $54.5 \%$ were married, $11.8 \%$ were in a relationship but unmarried and $19.5 \%$ were single; $14.3 \%$ of participants did not indicate their relationship status. All participants gave informed consent to participation.

\section{Materials}

Participants completed a questionnaire battery that consisted of demographic questions, including age, marital status and whether or not they had previously used CPAP. This information was verified against medical records. The battery consisted of the following questionnaires.

\section{Epworth Sleepiness Scale}

The Epworth Sleepiness Scale (ESS) [24] is a measure of subjective daytime sleepiness used for patients with OSA. Eight items are rated on a scale of $0-3$ (0: would never doze; 3 : high chance of dozing). Total scores range $0-24$, with higher scores indicating a greater propensity to fall asleep in different situations. It has norms available for the mild, moderate and severe categories of sleep apnoea. In samples of OSA, it shows high internal consistency [24] and correlates well with objective measures of sleep latency [25].

\section{Functional Outcomes of Sleep Questionnaire}

The Functional Outcomes of Sleep Questionnaire (FOSQ) [26] is a 30 -item survey of general quality of life in OSA and is a measure of perceived severity. The 30 items assessing five domains, including activity level, vigilance, intimacy, general productivity and social outcomes, are rated on a Likert scale ranging 1-4 (1: yes, extreme difficulty; 4: no difficulty). Lower scores represent greater impairment in functioning. A mean centred total score representing total functional difficulties related to sleepiness can be calculated. The internal consistency estimate ranges $0.81-0.90$ for the subscales and is 0.95 for the total score.

\section{Self-Efficacy Measure for Sleep Apnea}

The Self-Efficacy Measure for Sleep Apnea (SEMSA) [27] is a 26-item questionnaire assessing CPAP adherence-related cognitions. The measure is divided into three subscales that directly measure three constructs of the HBM, self-efficacy, risk perception and outcome expectancy. Items are rated on a Likert scale ranging 1-4, with higher scores indicating greater perceived self-efficacy, greater risk perception and higher outcome expectancies with treatment, respectively. Internal consistencies range $0.85-0.89$, and factor analysis confirms the three independent subscales.

\section{Depression Anxiety Stress Scales (21-item)}

The 21-item Depression Anxiety Stress Scales (DASS21) [28] is a self-report measure of symptoms of state, anxiety, depression and stress, rated on a Likert scale ranging 0-3 (0: did not apply to me at all; 3: applied to me very much or most of the time). Higher scores indicate higher severity ratings of depression, anxiety or stress symptoms over the past week. The DASS21 has good internal consistency estimates, ranging $0.73-0.81$, and the depression and anxiety subscales correlate well with common depression and anxiety inventories.

\section{Physiological indices}

Participants underwent standard clinical polysomnography (PSG) scored by trained sleep scientists using recommended guidelines [3]. Airflow was measured using both nasal pressure and naso-oral thermistors. Apnoea was defined as a reduction in both nasal pressure and thermistor readings to $<10 \%$ of baseline for $\geqslant 10 \mathrm{~s}$. The presence of respiratory effort was determined by inductive plethysmography and diaphragm electromyography. Hypopnoea was defined as a discernible reduction $(\sim 30 \%$ below baseline) in both nasal pressure and/or thermistor readings for $\geqslant 10 \mathrm{~s}$. These events were scored when they were associated (terminated) with an arousal and/or a desaturation of $\geqslant 3 \%$.

Measures obtained prior to and during the diagnostic PSG in the present study included RDI, arousal index (AI), percentage of total sleep time (TST) spent at $<80 \%$ arterial oxygen saturation $\left(\mathrm{Sa}, \mathrm{O}_{2}\right)$ and mean minimum $\mathrm{Sa}, \mathrm{O}_{2}$ during overnight PSG $\left(\mathrm{Sa}, \mathrm{O}_{2}, \mathrm{~min}\right)$. BMI was calculated based on height and weight measurements $\left(\mathrm{kg} \cdot \mathrm{m}^{2}\right)$. A CPAP titration PSG $\sim 2$ weeks after the diagnostic PSG allowed for the calculation of the therapeutic CPAP pressure $\left(\mathrm{cmH}_{2} \mathrm{O}\right)$ required to maintain patent airways throughout sleep. The pressure was titrated to a level that reduced the patient's RDI to $<5$ events $\cdot h^{-1}$ [29].

\section{Procedure}

The present study received ethical approval from the Human Research Ethics Committees of the University of Queensland (St Lucia, Australia) and the Prince Charles Hospital Health Services District (Chermside, Australia). Patients who met the inclusion criteria for the present study were invited to participate in the present research during their follow-up appointment with their sleep physician following their diagnostic PSG. Their diagnosis of OSA was explained to them in detail, and the recommended treatment option (CPAP) was described. An appointment for a CPAP titration study was made and patients were then given the questionnaire battery to complete at home.

Questionnaires were accompanied by a stamped addressed envelope. Mean adherence was assessed through a mailing $\sim 4$ months after the patients' diagnostic PSG, asking them to indicate the meter reading on their CPAP machine (after a mean of 122 days). This mailing coincided as closely as possible with a standard clinic with nurses at the Sleep Centre at the Prince Charles Hospital 12 weeks following treatment initiation (mean of 136 days). This face-to-face review between the nurse and the patient consisted of a machine reading to assess adherence, and troubleshooting problems encountered with the treatment. Patients who experienced difficulty in identifying the meter on their machine were assessed for adherence at this standard clinic. All meter readings collected during the mailing were compared to the data collected at the nurse clinic in order to ensure 
that patients were providing accurate and representative adherence data. After the nurse clinic, patients were encouraged to call the Sleep Centre and their mask supplier if further problems emerged. From the 2-month standard nurse clinic onwards, telephone consultations with the nurses (initiated by the patient) were the primary means by which any further contact with the patient occurred.

Patients who did not start using CPAP within the follow-up period were recorded as having a mean adherence rate of zero.

\section{Data analyses}

Relationships between predictors and mean duration of CPAP use per night (adherence) were assessed using Pearson's product-moment correlation coefficients, unpaired independent groups t-tests and ANOVA. Spearman's rank correlations were calculated for variables violating assumptions of normality and linearity (RDI, $\mathrm{Sa}_{2} \mathrm{O}_{2}, \mathrm{~min}, \mathrm{AI}$ and TST at $<80 \% \mathrm{Sa}_{2} \mathrm{O}_{2}$ ). Higher-order relationships between biomedical and HBM predictors were assessed using multiple regression analyses. Inspection of the residuals plot indicated that the assumption of homoscedasticity of residuals was met. The assumption of bivariate normality was also met. Cook's distance, an estimate of the change in regression coefficients should cases be removed, was nonsignificant. Tolerance levels did not fall below acceptable levels, indicating that collinearity and singularity were not present [30]. Therefore, all cases were retained for all analyses. The FOSQ total score was derived from subscales, all underpinning the perceived OSA severity construct; therefore, in order to maintain statistical power and minimise the use of extraneous overlapping variables, the total score was entered into the regression equation instead of the individual subscales [26].

Of the 77 participants in the present study, nine were found to have missing physiological data or incomplete questionnaires. Inspection of the data file suggested that the missing data were random, as supported by there being no significant differences in age, sex, BMI, RDI, ESS or adherence between incomplete and complete data sets. Therefore, cases with missing data were deleted listwise for the multiple regression analysis, leaving 68 cases for analysis. An a priori power analysis indicated that a minimum of 64 participants would be required in order to detect a moderate effect size of $r=0.30$ if power were set at 0.80 and $\alpha=0.05$ (one-tailed). Therefore, the current study attained an adequate sample size to detect significant effects should they exist.

\section{RESULTS}

Adherence at the 4-month follow-up and baseline CPAP and ESS scores are presented in table 1. Of the patients, $14(18 \%)$ received an adherence rating of 0 as they had not initiated CPAP during the follow-up period, 21 (27\%) had mean meter readings of $1.0-4.5 \mathrm{~h} \cdot$ night $^{-1}, 35(45 \%)$ had meter readings of 4.5-8.0 $\mathrm{h} \cdot$ night $^{-1}$ and the remaining seven $(10 \%)$ had meter readings of $8.0-11.1 \mathrm{~h} \cdot$ night $^{-1}$.

Multiple regression analyses were conducted in order to assess the relative importance of the HBM predictors in explaining CPAP adherence, with biomedical indices included and then removed from the analyses. As demonstrated in table 2, HBM predictors (risk, outcome expectancy, FOSQ and self-efficacy) and biomedical indices (RDI, AI, BMI, ESS score, $\mathrm{Sa}_{\mathrm{a}} \mathrm{O}_{2}$, min and percentage TST at $<80 \% \mathrm{Sa}, \mathrm{O} 2)$ together explained a significant $31.8 \%$ of the variance in CPAP adherence $(\mathrm{R}=0.56 ; F(10$, $57)=2.66 ; \mathrm{p}=0.01)$. Risk and outcome expectancy explained the most variance in adherence $(\mathrm{p}<0.05)$, followed by FOSQ total score $(p=0.065)$. Self-efficacy did not contribute to adherence in the model, and nor did any of the biomedical indices.

Contrary to expectation, a lower perceived risk of negative health consequences was associated with greater adherence in the context of the HBM. When considered in a bivariate relationship with adherence, it was not a significant predictor. The bivariate correlation between perceived risk and adherence is provided in figure 2.

In order to determine the contribution of HBM predictors to adherence without the inclusion of biomedical predictors, a regression analysis was completed with risk, outcome expectancy, self-efficacy and FOSQ total score as predictors of CPAP adherence (table 3 ). These four constructs explained a significant $21.8 \%$ of the variance in CPAP adherence $(\mathrm{R}=0.48 ; F(4$, $70)=4.88 ; \mathrm{p}=0.002$ ). Risk, outcome expectancy and FOSQ total score all explained a significant and unique proportion of the variance in adherence (all $\mathrm{p}<0.05)$. Self-efficacy did not explain a significant proportion of the variance in adherence.

Significant correlations were found between adherence and $\mathrm{HBM}$ constructs measured prior to the patient trying CPAP therapy (table 4). A greater mean use of CPAP per night was associated with a higher outcome expectancy of treatment, lower pretreatment activity levels, lower self-rated intimacy levels and lower general productivity throughout the day. Significant intercorrelations between the HBM constructs were also found, with self-efficacy highly correlated with greater expected benefits with treatment and a higher perceived risk of negative health consequences. As demonstrated in table 4 , higher risk perception and higher outcome expectancies with treatment were associated with greater functional limitations in the areas of activity, vigilance, intimacy, general productivity and social outcome.

There were no significant differences between males and females in their mean adherence $(t(75)=0.29 ; p=0.77 ;$ $\left.p \eta^{2}=0.001\right)$. There was no difference in adherence between individuals of different relationship status $(F(3,62)=0.90$; $\left.\mathrm{p}=0.45 ; \mathrm{p} \eta^{2}=0.04\right)$. As expected, there was no significant direct relationship between adherence and age, BMI, CPAP, ESS, RDI, $\mathrm{Sa}_{2} \mathrm{O}_{2}, \mathrm{~min}$, AI or percentage TST at $<80 \% \mathrm{Sa}_{1} \mathrm{O}_{2}$ (table 5). Furthermore, there were no significant direct relationships between adherence and the psychological variables of

\begin{tabular}{|c|c|c|}
\hline TABLE 1 & $\begin{array}{l}\text { Adherer } \\
\text { (CPAP) } \\
\text { score }\end{array}$ & $\begin{array}{l}\text { positive airway pressure } \\
\text { eepiness Scale (ESS) }\end{array}$ \\
\hline \multicolumn{2}{|c|}{ Adherence $\mathrm{h} \cdot$ night $^{-1}$} & $4.57 \pm 2.87(0-11.10)$ \\
\hline \multicolumn{2}{|c|}{ CPAP pressure $\mathrm{cmH}_{2} \mathrm{O}$} & $11.68 \pm 2.84(6.00-19.00)$ \\
\hline \multicolumn{2}{|c|}{ ESS score } & $11.93 \pm 5.22(2.00-21.00)$ \\
\hline
\end{tabular}




\begin{tabular}{|c|c|c|c|c|}
\hline \multirow[t]{2}{*}{ TABLE 2} & \multicolumn{4}{|c|}{$\begin{array}{l}\text { Multiple regression analysis including health } \\
\text { belief model (HBM) constructs and biomedical } \\
\text { indices }\end{array}$} \\
\hline & & $\beta(95 \% \mathrm{Cl})$ & $s r^{2}$ & t-value \\
\hline \multicolumn{5}{|c|}{ Biomedical indices } \\
\hline $\mathrm{RDI}$ & & 0.05 & 0.02 & 0.19 \\
\hline $\mathrm{Al}$ & & -0.17 & -0.08 & -0.70 \\
\hline BMI & & 0.02 & 0.01 & 0.13 \\
\hline ESS score & & -0.02 & -0.01 & -0.13 \\
\hline $\mathrm{Sa}, \mathrm{O}_{2}, \min$ & & -0.02 & -0.01 & -0.11 \\
\hline TST at $<8 C$ & $\mathrm{Sa}, \mathrm{O}_{2}$ & -0.19 & -0.12 & -1.13 \\
\hline \multicolumn{5}{|c|}{ HBM indices } \\
\hline Risk & & $-0.46(-0.75--0.17)$ & -0.34 & $-3.06^{\star \star}$ \\
\hline Outcome e & pectancy & $0.44(0.13-0.75)$ & 0.296 & $2.71^{\star *}$ \\
\hline FOSQ total & core & $-0.30(-0.61-0.01)$ & -0.21 & -1.88 \\
\hline Self-efficac & & 0.01 & 0.004 & 0.04 \\
\hline
\end{tabular}

Cl: confidence interval; $\mathrm{sr}^{2}$ : semipartial correlation coefficient; RDI: respiratory disturbance index; Al: arousal index; BMI: body mass index; ESS: Epworth Sleepiness Scale; $\mathrm{Sa}_{1} \mathrm{O}_{2}$,min: minimum arterial oxygen saturation $\left(\mathrm{Sa}, \mathrm{O}_{2}\right)$; TST: total sleep time; FOSQ: Functional Outcomes of Sleep Questionnaire. $R=0.56^{\star *} . * *: p<0.01$

depression $(\mathrm{r}=0.07 ; \mathrm{p}=0.58)$, anxiety $(\mathrm{r}=-0.08 ; \mathrm{p}=0.52)$ and stress $(r=0.04 ; p=0.78)$.

Inspection of intercorrelation matrices revealed that a higher BMI prior to treatment was associated with greater perceived risk $(\mathrm{r}=0.27 ; \mathrm{p}<0.05)$, lower activity levels $(\mathrm{r}=-0.29 ; \mathrm{p}<0.05)$, poorer vigilance $(\mathrm{r}=-0.23 ; \mathrm{p}<0.05)$, lower productivity throughout the day $(\mathrm{r}=-0.23 ; \mathrm{p}<0.01)$ and higher depression $(\mathrm{r}=0.33 ; \mathrm{p}<0.01)$, anxiety $(\mathrm{r}=0.36 ; \mathrm{p}<0.01)$ and stress scores $(\mathrm{r}=0.32 ; \mathrm{p}<0.01)$. Higher ESS scores were associated with greater perceived risk $(\mathrm{r}=0.29 ; \mathrm{p}<0.05)$, higher outcome expectancy with treatment $(\mathrm{r}=0.27 ; \mathrm{p}<0.05)$, lower activity levels $(r=-0.42 ; p<0.001)$, poorer vigilance $(r=-0.58 ; p<0.01)$, greater intimacy-related concerns $(r=-0.30 ; p<0.05)$, lower general productivity $(\mathrm{r}=-0.43 ; \mathrm{p}<0.01)$ and a poorer self-rated social outcome $(\mathrm{r}=-0.38 ; \mathrm{p}<0.01)$.

\section{DISCUSSION}

The findings of the present study support the utility of the HBM in the early prediction of CPAP adherence [23]. Patients' outcome expectancies prior to using CPAP and perception of risk, as well as perceived functional limitations due to sleepiness, such as in the areas of intimacy, activity levels and general productivity, all uniquely predicted CPAP initiation and adherence. As supported by a growing evidence base, biomedical indices of disease severity did not predict $>10 \%$ of the variance in CPAP adherence when $\mathrm{HBM}$ variables were included in regression models [7, 23].

The HBM predictors alone explained $21.8 \%$ of the variance in CPAP adherence, whereas biomedical and HBM predictors together explained $31.8 \%$ of the variance in CPAP adherence. This extends previous research investigating prediction before [18] and after experience with CPAP $[13,15,19]$. The fact that

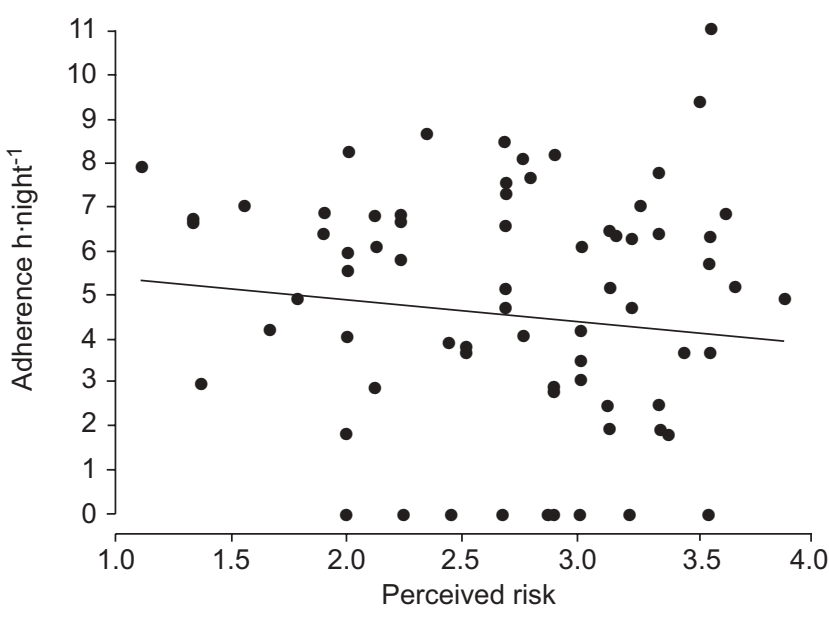

FIGURE 2. Scatter diagram showing correlation between perceived risk (higher values indicate higher risk) and adherence to continuous positive airway pressure therapy. _- line of best fit.

outcome expectancy prior to trying CPAP, as well as low perceived activity levels, low general productivity and intimacy concerns, predicted use of the treatment 4 months later is of great significance in terms of early identification and support of patients with factors that are associated with low adherence.

Physiological and disease severity variables, such as RDI, AI and drops in $\mathrm{Sa}_{2} \mathrm{O}_{2}$, during sleep were unimportant in the early prediction of CPAP adherence. This supports research suggesting that the patient's perceived need for treatment is not directly associated with objective measures of the severity of the disorder (their objective need for treatment) [2, 14]. If patients do not see themselves as having limitations in functioning as a direct result of the disorder, and if expectations for improvements in these functional limitations are low, consistent CPAP use is unlikely. The present study found that depression, anxiety and stress did not individually predict CPAP adherence.

The ESS score was not a significant predictor of CPAP adherence, despite its prevalent use in sleep medicine as an index of subjective sleepiness. ESS measured prior to CPAP treatment is an inconsistent predictor of adherence across the literature. Some studies have found it to predict adherence [31]

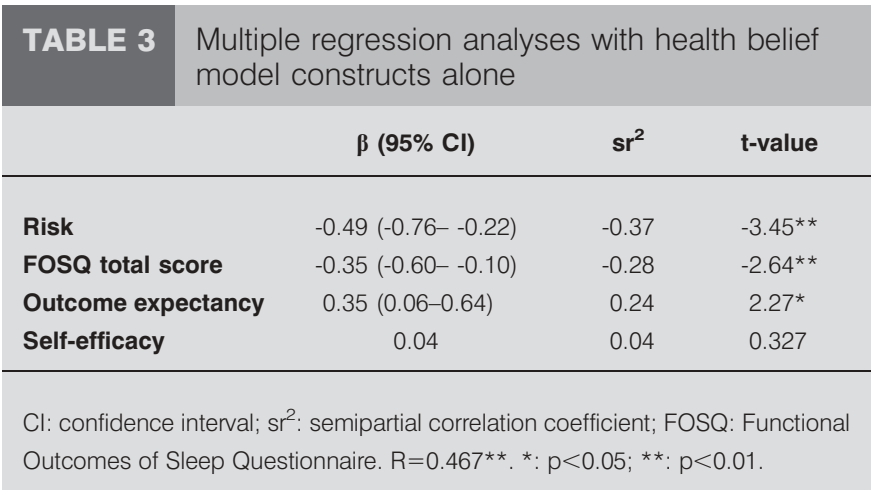


TABLE 4 Bivariate correlations between health belief model constructs and adherence

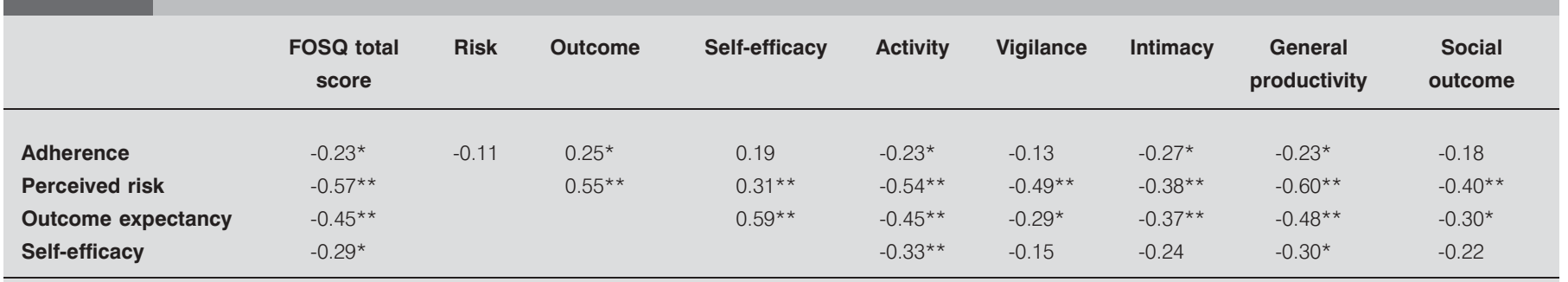

FOSQ: Functional Outcomes of Sleep Questionnaire. *: $p<0.05 ;{ }^{*}$ : $p<0.01$.

and patient self-referrals for CPAP treatment [32]. Other studies report no effect of ESS score prior to treatment on determining CPAP compliance [13, 33]. However, studies assessing changes in patient perceptions following treatment initiation have found that an improved ESS score often predicts current CPAP use [9, 17, 31]. Thus, the present study supports research suggesting that initial ESS score, along with many other biomedical indices of disease severity, are inconsistent early predictors of CPAP adherence. However, changes in these scores with treatment may be useful in subsequent prediction.

Contrary to the present authors' expectation, a lower perceived risk of negative health consequences if OSA remained untreated was associated with greater adherence. This finding is somewhat perplexing given the strong relationships between subjective functional limitations due to sleepiness and greater adherence, as well as higher outcome expectancies with higher adherence rates. The sample utilised in the present study displayed similar demographic and adherence rates to those in previous studies [5, 6, 8-11, 15, 23], suggesting that the present study had captured a fairly typical OSA population. Therefore, these findings are unlikely to be attributable to sampling error. Further investigation of this finding is clearly needed.

One avenue of investigation may be in the context of OSA as a lifestyle disease with associations with other health problems, such as diabetes, heart disease and obesity. Patients may be

\begin{tabular}{lc} 
TABLE 5 & $\begin{array}{c}\text { Bivariate correlations between demographic and } \\
\text { disease severity variables and adherence }\end{array}$ \\
\hline Variables & ${\text { Adherence } \mathbf{h} \cdot \text { night }^{-1}}^{-1}$ \\
\hline Age & -0.12 \\
BMI & -0.08 \\
CPAP & -0.16 \\
ESS score & 0.06 \\
Sa, $\mathbf{O}_{2}$,min & $0.20^{\#}$ \\
Al & $-0.13^{\#}$ \\
TST at $<\mathbf{8 0} \% \mathbf{S a}_{\mathbf{2}} \mathbf{O}_{\mathbf{2}}$ & $-0.06^{\#}$ \\
RDI & $-0.13^{\#}$ \\
\hline
\end{tabular}

BMI: body mass index; CPAP: continuous positive airway pressure; ESS: Epworth Sleepiness Scale; $\mathrm{Sa}_{1} \mathrm{O}_{2}$,min: minimum arterial oxygen saturation $\left(\mathrm{Sa}_{2} \mathrm{O}_{2}\right)$; Al: arousal index; TST: total sleep time; RDI: respiratory disturbance index. ${ }^{\#}$ : rank correlations. overwhelmed by several negative health messages and treatment regimens, and this may serve to decrease rather than increase motivation to adhere to treatment. Coordination of health services and prioritisation of treatment goals for individual patients to address one or two key underlying problems, such as poor diet and lack of exercise, may be more successful and less overwhelming to the patient than the prospect of medication, CPAP and potential surgery to target these issues individually.

The limitations of the present study are directly tied in with the directions for future research. The present study constituted an investigation into the HBM using available measures, namely self-efficacy, perceived risk (susceptibility), functional outcomes (severity) and outcome expectancies (benefits). A modest sample size was utilised in the study; however, confidence intervals around the outcome variables and a priori power analysis indicated that the sensitivity for detecting important relationships with adherence was adequate. The use of self-report measures of HBM constructs may represent another limitation of the present study; however, the use of validated measures overcomes some of the subjectivity associated with this. Moreover, beliefs testing can only occur through self-report measures. The present authors have developed OSA-specific measures for the barriers and cues to action constructs in order to fully assess the power of HBM constructs in the early prediction of CPAP initiation and adherence in future research. The potential clinical applications of a well-described HBM would include the development of cut-off points for different expected levels of adherence to treatment (based on arborescence analysis, for example).

The finding that motivations to use continuous positive airway pressure are associated with patients' perceptions of disease severity and outcome expectancies, rather than objective measures of severity (such as respiratory disturbance index, arousal index and oxygen desaturation), supports the call in the literature for the identification of psychological predictors of adherence to continuous positive airway pressure that are amenable to intervention [7, 15, 34]. The present findings suggest that perceptions of risk, outcome expectancies with treatment and functional limitations in daily life are important early predictors of initiation and continued use of continuous positive airway pressure. Early identification of these beliefs, and assistance in overcoming barriers to acceptance by facilitating the development of realistic and positive expectations for improvements in daily life as a result of using the 
treatment, will increase adherence to continuous positive airway pressure therapy.

\section{ACKNOWLEDGEMENTS}

The authors would like to acknowledge and sincerely thank the supporting sleep physicians and nurses of the Prince Charles Hospital (Chermside, Australia) who contributed to the present research.

\section{REFERENCES}

1 Chesson A, Ferber R, Fry J, et al. Practice parameters for the indications for polysomnography and related procedures. Sleep 1997; 20: 406-422.

2 American Academy of Sleep Medicine. The International Classification of Sleep Disorders: Diagnostic and Coding Manual. 2nd Edn. Westchester, American Academy of Sleep Medicine, 2005.

3 American Academy of Sleep Medicine. Sleep-related breathing disorders in adults: recommendations for syndrome definition and measurement techniques in clinical research. Sleep 1999; 22: 667-689.

4 Young T, Peppard P, Gottlieb D. Epidemiology of obstructive sleep apnea. Am J Respir Crit Care Med 2002; 165: 1217-1239.

5 Collard P, Pieters T, Aubert G, Delguste P, Rodenstein A. Compliance with nasal CPAP in obstructive sleep apnea patients. Sleep Med Rev 1997; 1: 33-44.

6 Zozula R, Rosen R. Compliance with continuous positive airway pressure therapy: assessing and improving treatment outcomes. Curr Opin Pulm Med 2001; 7: 391-398.

7 Engleman H, Wild M. Improving CPAP use by patients with the sleep apnoea/hypopnoea syndrome (SAHS). Sleep Med Rev 2003; 7: 81-99.

8 Krieger J. Long-term compliance with nasal continuous positive airway pressure (CPAP) in obstructive sleep apnea patients and nonapneic snorers. Sleep 1992; 15: S42-S46.

9 Lewis K, Seale L, Bartle I, Watkins A, Ebden P. Early predictors of CPAP use for the treatment of obstructive sleep apnea. Sleep 2004; 27: 134-138.

10 Pieters T, Collard P, Aubert G, Dury M, Delguste P, Rodenstein A. Acceptance and long-term compliance with nCPAP in patients with obstructive sleep apnoea syndrome. Eur Respir J 1996; 9: 939-944.

11 Reeves-Hoche M, Meck R, Zwillich C. Nasal CPAP: an objective evaluation of patient compliance. Am J Respir Crit Care Med 1994; 149: 149-154.

12 Haniffa M, Lasserson T, Smith I. Interventions to improve compliance with continuous positive airway pressure for obstructive sleep apnoea. Cochrane Database Syst Rev 2004; 4: CD003531.

13 Stepnowsky C, Marler M, Ancoli-Isreal S. Determinants of nasal CPAP compliance. Sleep Med 2002; 3: 239-247.

14 Chervin R, Aldrich M. The Epworth Sleepiness Scale may not reflect objective measures of sleepiness or sleep apnea. Neurology 1999; 52: 125-131.

15 Aloia M, Arnedt T, Stepnowsky C, Hecht J, Borrelli B. Predicting treatment adherence in obstructive sleep apnea using principles of behavior change. J Clin Sleep Med 2005; 1: 346-353.
16 Edinger J, Carwile S, Miller P, Hope V, Mayti C. Psychological status, syndromatic measures, and compliance with nasal CPAP therapy for sleep apnea. Percept Mot Skills 1994; 78: 1116-1118.

17 McFadyen T, Espie C, McArdle N, Douglas N, Engleman H. Controlled, prospective trial of psychosocial function before and after continuous positive airway pressure therapy. Eur Respir J 2001; 18: 996-1002.

18 Stepnowsky C, Bardwell W, Moore P, Ancoli-Isreal S, Dimsdale J. Psychologic correlates of compliance with continuous positive airway pressure. Sleep 2002; 25: 758-762.

19 Wild M, Engleman H, Douglas N, Espie C. Can psychological factors help us to determine adherence to CPAP: a prospective study. Eur Respir J 2004; 24: 461-465.

20 Smith S, Lang C, Sullivan K, Warren J. Two new tools for assessing patients' knowledge and beliefs about obstructive sleep apnea and continuous positive airway pressure therapy. Sleep Med 2004; 5: 359-367.

21 Clark N, Becker M. Theoretical models and strategies for improving adherence and disease management. In: Shumaker S, Schron E, Ockene J, McBee W, eds. The Handbook of Health Behavior Change. 2nd Edn. New York, Springer Publishing Company, 1998; pp. 5-32.

22 Quine L, Rutter D, Arnold L. Comparing the theory of planned behaviour and the health belief model: the example of safety helmet use among schoolboy cyclists. In: Norman P, Abraham C, Connor M, eds. Understanding and Changing Health Behaviour: From Health Beliefs to Self-Regulation. Amsterdam, Harwood Academic Publishers, 2000; pp. 73-98.

23 Sage C, Southcott A, Brown S. The health belief model and compliance with CPAP treatment for obstructive sleep apnoea. Behav Change 2001; 18: 177-185.

24 Johns M. A new method for measuring daytime sleepiness: the ESS. Sleep 1991; 14: 540-545.

25 Miletin M, Hanly P. Measurement properties of the Epworth Sleepiness Scale. Sleep Med 2003; 4: 195-199.

26 Weaver T, Laizner A, Evans L, et al. An instrument to measure functional status outcomes for disorders of excessive sleepiness. Sleep 1997; 20: 835-843.

27 Weaver T, Maislin G, Dinges D, et al. Self-efficacy in sleep apnea: instrument development and patient perceptions of obstructive sleep apnea risk, treatment benefit, and volition to use continuous positive airway pressure. Sleep 2003; 26: 727-732.

28 Lovibond S, Lovibond P. Manual for the Depression Anxiety Stress Scales. Sydney, The Psychology Foundation of Australia, Inc., 1995.

29 Malhotra A, Ayas N, Epstein L. The art and science of continuous positive airway pressure therapy in obstructive sleep apnea. Curr Opin Pulm Med 2000; 6: 490-495.

30 Tabachnick B, Fidell L. Using Multivariate Statistics. 4th Edn. Boston, Allyn \& Bacon, 2001.

31 Engleman H, Asgari-Jirhandeh N, McLeod A, Ramsay C, Deary I, Douglas N. Self-reported use of CPAP and benefits of CPAP therapy: a patient survey. Chest 1996; 109: 1470-1476.

32 Hoy C, Vennelle R, Kingshott R, Engleman H, Douglas N. Can intensive support improve continuous positive 
airway pressure use in patients with the sleep apnea/ hypopnea syndrome? Am J Respir Crit Care Med 1999; 159: 1096-1100.

33 Hui D, Choy K, Li T, et al. Determinants of continuous positive airway pressure compliance in a group of Chinese patients with obstructive sleep apnea. Chest 2001; 120: 170-176.

34 Aloia M, Arnedt T, Riggs R, Hecht J, Borrelli B. Clinical management of poor adherence to CPAP: motivational enhancement. Behav Sleep Med 2004; 2: 205-222. 